\title{
Distribution of carbohydrates in the zona pellucida of human oocytes
}

\author{
B. Bar-Shira Maymon ${ }^{1}$, R. Maymon ${ }^{2}$, I. Ben-Nun ${ }^{2}$, Y. Ghetler ${ }^{2}$, \\ R. Shalgi ${ }^{3}$ and E. Skutelsky ${ }^{1 *}$ \\ Departments of ${ }^{\mathrm{I}}$ Pathology and ${ }^{3}$ Embryology, Sackler School of Medicine, Tel Aviv University, \\ Ramat Aviv 69978, Israel; and ${ }^{2}$ IVF Unit, Sapir Medical Center, Kfar Sava, Israel
}

\begin{abstract}
The purpose of the present study was to investigate the distribution pattern of carbohydrates in the zona pellucida of human oocytes using lectins and ruthenium red as histochemical probes. For lectin analyses, oocytes that failed to undergo fertilization following in vitro insemination were collected, washed, fixed with glutaraldehyde and embedded in araldite. For ruthenium red labelling, the oocytes were fixed with glutaraldehyde containing ruthenium red, post-fixed with $\mathrm{OsO}_{4}$ and embedded in araldite. Araldite sections $(1 \mu \mathrm{m})$ were de-resined with sodium methoxide, rehydrated, labelled with ten different biotinylated lectins as probes and avidin-biotin-peroxidase complex as visualant, and examined under a light microscrope. The zonae pellucidae of all oocytes studied exhibited a common lectin-binding pattern, expressed in intense binding of lectins from Concanavalia ensiformis (ConA), Lens culinaris (LCA), Ricinus communis (RCA-I), wheat germ agglutinin (WGA), and of succinylated WGA (S-WGA). Peanut lectin (PNA) bound to the zona pellucida only after neuraminidase treatment, whereas the lectins from Griffonia simplisifolia (GS-I), Dolichos biflorus (DBA), Ulex europhaeus (UEA-I) and soybean (SBA) did not bind at all. There was almost no binding of ruthenium red to the matrix of the zona pellucida. The results indicate that the human zona pellucida is characterized by normally exposed mannosyl, $N$-acetylglucosaminyl and $\beta$-galactosyl residues. In addition, it contains masked $\beta \mathrm{Gal}-(1-3) \mathrm{GalNAc}$ sugar sequences that can be exposed only after removing terminal sialic acid residues. The presence of sialic acid in the human zona pellucida, which is not expressed as an increase in the binding capacity of the polycationic probe (ruthenium red), has not been reported in any of the mammalian zonae pellucidae previously studied.
\end{abstract}

\section{Introduction}

The mammalian oocyte is surrounded by a transparent, extracellular coat called the zona pellucida, which plays an important role during fertilization. It restricts interspecies fertilization, induces the acrosome reaction in bound spermatozoa, and assists in establishing the zona block to polyspermy after sperm penetration (Yanagimachi, 1988; Saling, 1989).

In a wide variety of species studied, the zona pellucida is composed of only a few glycoproteins. It has been suggested that carbohydrate determinants of the zona pellucida glycoproteins are involved in the sperm-egg interaction (Macek and Shur, 1988; Miller and Ax, 1990; Wassarman, 1990). The most studied mammal in this respect is the mouse, in which the zona pellucida has been shown to consist of three glycoproteins, $\mathrm{ZP1}, \mathrm{ZP2}$ and $\mathrm{ZP} 3$, each of which presents a unique polypeptide chain and oligosaccharides (Wassarman, 1988). It has been demonstrated that the sperm-egg interaction in the mouse involves specific sugar residues such as $\alpha$-galactose (Gal) of O-linked oligosaccharides of ZP3 (Bleil and Wassarman,

*Correspondence.

Received 28 January 1994.
1988) or $\mathrm{N}$-acetylglucosaminyl (GlcNAc) residues (Miller et al., 1993) serving as sperm-binding sites, and that it also involves the polypeptide chain as an inducer for the acrosome reaction (Florman et al., 1984; Florman and Wassarman, 1987).

Skutelsky et al. (1994) demonstrated that the distribution of zona pellucida carbohydrates from oocytes of different mammals were different, suggesting that these differences might be important in the control of species-specific gamete interactions. Shabanowitz and O'Rand (1988) studied the composition of the human zona pellucida surrounding fertilized and unfertilized eggs. They reported that, under reducing conditions, zonae from unfertilized eggs can be separated into three acidic proteins, also designated $\mathrm{ZP1}, \mathrm{ZP} 2$ and $\mathrm{ZP} 3$. It was later reported that ZP3 consists of two isomer chains (Shabanowitz, 1990); its amino acid sequence was also analysed (Chamberlin and Dean, 1990).

It may be assumed that, as in other mammals, the interaction between gametes in human reproduction might also depend on species-specific recognition by carbohydrates expressed on the zona pellucida surface, and on changes in the distribution pattern of these carbohydrates following maturation and fertilization. Thus, it is important to localize and characterize the spatial distribution and availability of specific sugar residues 
Table 1. Lectins used for identifying carbohydrate residues in zona pellucida of human oocytes

\begin{tabular}{|c|c|c|c|c|c|}
\hline Origin of lectin & Common name & Acronym & Concentration $\left(\mu \mathrm{g} \mathrm{ml}^{-1}\right)$ & Major sugar specification ${ }^{a}$ & Binding inhibitor \\
\hline Arachis hypogea & Peanut & PNA & 20 & $\beta \mathrm{Gal}-(1-3) \mathrm{GalNAc}$ & Lactose \\
\hline Griffonia simplicifolia & Griffonia & GS-I & 50 & $\alpha-\mathrm{D}-\mathrm{Gal}$ & Lactose \\
\hline Concanavalia ensiformis & Jack bean & ConA & 10 & aD-Glc, a-D-Man & $\alpha$-D-methyl-Man \\
\hline Dolichos biflorus & Horse gram & DBA & 10 & $\alpha$-D-GalNAc & $\alpha$-D-GalNAc \\
\hline Glycine max & Soybean & $\mathrm{SBA}$ & 10 & $\alpha-\mathrm{D}-\mathrm{GalNAc}, \mathrm{a}-\mathrm{D}-\mathrm{Gal}$ & $\alpha$-D-GalNAc \\
\hline Lens culinaris & Common lentil & $\mathrm{LCA}$ & 10 & $a-D-G l c, a-D-M a n$ & $\alpha$-D-methyl-Man \\
\hline Ricinus communis & Castor bean & RCA-I & 50 & $\beta-\mathrm{D}-\mathrm{Gal}$ & Lactose \\
\hline Triticum vulgaris & Wheat germ & WGA & 50 & {$[\beta-(1-4)-\mathrm{D}-\mathrm{GlcNAc}]_{2} \mathrm{NeuNAc}$} & NeuNAc \\
\hline Trificum vulgaris & Succinyl-WGA & S-WGA & 10 & {$[\beta-(1-4)-\mathrm{D}-\mathrm{GlcNAc}]_{2}$} & $\beta$-D-GlcNAc \\
\hline Ulex europaeus & Gorse & UEA-I & 10 & $\alpha$-L-fucose & $\alpha$-L-fucose \\
\hline
\end{tabular}

${ }^{a}$ Gal: galactose; GaiNAc: $N$-acetylgalactosamine; GlcNAc: $N$-acetylglucosamine; Man: mannose; NeuNAc: $N$-acetylneuraminic acid (sialic acid).

in the human zona pellucida, and to detect possible changes in their distribution in correlation with developmental processes.

Lectins are sugar-binding proteins or glycoproteins of nonimmune origin that agglutinate cells or precipitate glycoconjugates having saccharides of appropriate complementarity (Goldstein et al., 1980). In numerous studies, plant lectins have been used to inhibit sperm-egg adhesion (Oikawa et al., 1973; Rosati et al., 1978; Bolwell et al., 1979; Ahuja and Bolwell, 1983; Barnum and Brown, 1983; Catt et al., 1983; Del Pino and Cabada, 1987; Mori et al., 1989). Lectins have been used to characterize the zona pellucida in hamsters, mice and pigs with light and electron microscopes (Nicolson et al., 1975; Dunbar et al., 1980; Wu et al., 1984; Kan et al., 1990). We analysed the distribution of lectinbinding patterns in various mammalian oocytes with both types of microscope (Shalgi et al., 1991; Skutelsky, et al., 1994). In the present study, we examined the distribution and availability of specific sugar residues in the zona pellucida of human oocytes. Since certain sugars, such as sialic acid or heparan sulfate, largely contribute to the charge properties of the oocyte membrane and extracellular matrix (Skutelsky ef al., 1992), we also used the polycationic histochemical probe ruthenium red (Luft, 1971), which is known to interact with sialic acid residues, to characterize the polyanionic constituents on the zona pellucida and associated structures.

\section{Materials and Methods}

In vitro fertilization protocol

Women $(n=15)$ scheduled for in vitro fertilization underwent controlled hyperstimulation with a $\mathrm{GnRH}$ analogue (either D-Trp ${ }^{6}$ (Decapeptyl; Ferring AG, Kiel) or buserelin acetate (Superfect; Hoechst AG, Frankfurt on Main)), and human menopausal gonadotrophin (hMG) (Pergonal, Teva Ltd, Kfar Sava), as reported by Ben-Nun et al. (1990). The oocytes were inseminated $4-6 \mathrm{~h}$ after oocyte aspiration with at least $10^{-5}$ motile spermatozoa obtained from semen samples by a swim-up procedure. Ham's F-10 solution (Irvine
Scientific, Irvine, CA), supplemented with $10 \%$ patient serum and immediately centrifuged at $1000 \mathrm{~g}$ for $2 \mathrm{~min}$ and heat inactivated was used as a culture medium. The oocytes were dissected out of the surrounding cumulus mass $16-18 \mathrm{~h}$ after insemination and examined for the presence of pronuclei. Those oocytes lacking pronuclei (categorized as 'not fertilized') were washed in PBS (pH 7.4) and fixed with $2.5 \%$ glutaraldehyde in $0.1 \mathrm{~mol}$ phosphate buffer $1^{-1}$ ( $\mathrm{pH}$ 7.4). All specimens were studied with the consent of the patients and represent material that would normally have been discarded.

\section{Ruthenium red labelling}

The oocytes were washed in PBS, fixed for $3 \mathrm{~h}$ with $2.5 \%$ glutaraldehyde containing $0.05 \%$ ruthenium red, washed with $\mathrm{PBS}$, and post-fixed for $1 \mathrm{~h}$ with $1 \% \mathrm{OsO}_{4}$ in Veronal-acetate buffer ( $\mathrm{pH} 7.4$ ) containing 0.05\% ruthenium red (Luft, 1971). The samples were then dehydrated in ethanol and propylene oxide and embedded in araldite.

\section{Light microscope histochemistry}

For araldite-embedded material, $I \mu \mathrm{m}$ thick sections were cut using a LKB ultramicrotome. The resin was removed by mounting the sections on microscope slides, treating with sodium methoxide, washing with methanol-benzene and acetone, and rehydrating by immersion in PBS. Endogenous peroxidase was blocked by incubation in $2 \% \mathrm{H}_{2} \mathrm{O}_{2}$ at $37^{\circ} \mathrm{C}$ for $10 \mathrm{~min}$. The sections were then covered with $1 \%$ BSA in PBS for $10 \mathrm{~min}$, the excess was shaken off, and the slides around the tissue sections were blotted. They were then incubated with one of ten different biotin-labelled lectins (Vector Laboratories, Burlingame, CA; Table 1) for $30 \mathrm{~min}$, washed three times in PBS and incubated with avidin-biotin-peroxidase complex (Vector Laboratories) for $30 \mathrm{~min}$, followed by three washes with PBS. The visualant, horseradish peroxidase, was activated by incubation for $8 \mathrm{~min}$ in PBS solution containing diaminobenzidine and $\mathrm{H}_{2} \mathrm{O}_{2}$. After washing in tap water for $5 \mathrm{~min}$, the sections were dehydrated and covered with a Merkoglass coverslip. 
(a)

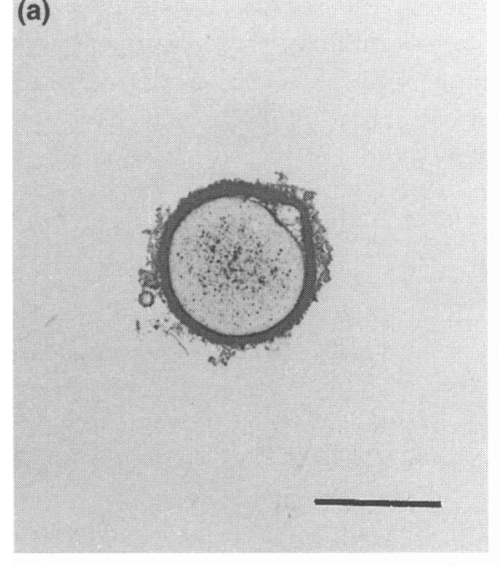

(d)

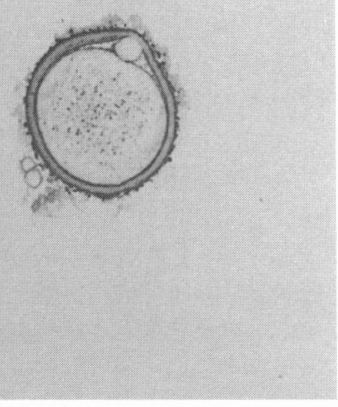

(b)

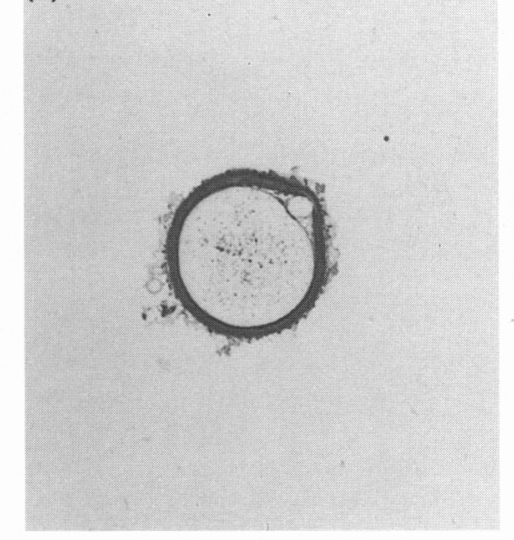

(c)

(e)

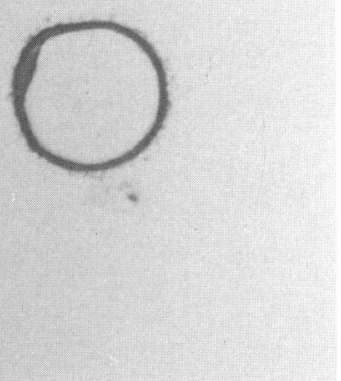

Fig. 1. Semithin araldite sections of human oocytes, stained with (a) concanavalin A (ConA), (b) common lentil lectin (LCA), (c) castor bean lectin (RCA-I), (d) wheat germ agglutinin (WGA), and (e) succinylated WGA. The zona pellucida of all the oocytes is intensely stained by the lectins. The binding of WGA is mainly confined to the outer and inner regions of the zona pellucida. Scale bar represents $100 \mu \mathrm{m}$.

The lectins used in this study, their acronyms, concentrations, major sugar specificities, and corresponding sugars that inhibit their binding are given in Table 1 . The concentrations selected were to reduce background binding to a minimum, but were rich enough to detect relatively low concentrations of specific sugar residues. Incubation of lectins with $0.2 \mathrm{~mol}$ of corresponding sugar haptens $\mathrm{I}^{-1}$ (Table 1 ) before and during the application of the lectin solution to the tissue sections served as specific controls. Incubation of avidinbiotin-peroxidase complex alone served as a nonspecific control. The lectin-stained slides were examined under a microscope and the staining was defined as positive or negative. The degree of staining intensity was appreciated semiquantitatively as weak, moderate or strong.

\section{Electron microscopy}

For evaluation of ruthenium red binding, ultrathin sections, $60 \mathrm{~nm}$, of the araldite-embedded oocytes were prepared using a LKB-V ultramicrotome equipped with a diamond knife. The sections were stained with uranyl acetate and lead citrate and examined under a JEOL-100B electron microscope at $80 \mathrm{kV}$.

\section{Results}

\section{Binding of lectins to the zona pellucida}

The study was carried out on oocytes collected from 15 women, and included 32 oocytes that were singly embedded in araldite. The use of araldite as an embedding medium allowed the histochemical analyses to be performed on single oocytes, and the analyses to be performed on semithin ( $<1 \mu \mathrm{m}$ thick) sections. This approach provided a considerably improved resolution of the histochemical reactions compared with paraffin wax sections.

Ten different lectins (Table 1) were examined for their capacity to bind to ovulated human oocytes. In all the oocytes studied, there was an intense binding of specific lectins to the zona pellucida, and the lectin-binding patterns of the different oocytes studied were very similar. The zona pellucida of all the oocytes displayed intense binding capacity for five of the lectins studied: Concanavalin A (ConA; Fig. 1a), the common lentil lectin LCA (Fig. Ib), the castor bean lectin RCA-I (Fig. Ic), wheat germ agglutinin (WGA; Fig. Id) and succinylWGA (Fig. 1e).

The binding of ConA, LCA and RCA-I were generally evenly distributed throughout the entire thickness of the zona 
(a)

(b)
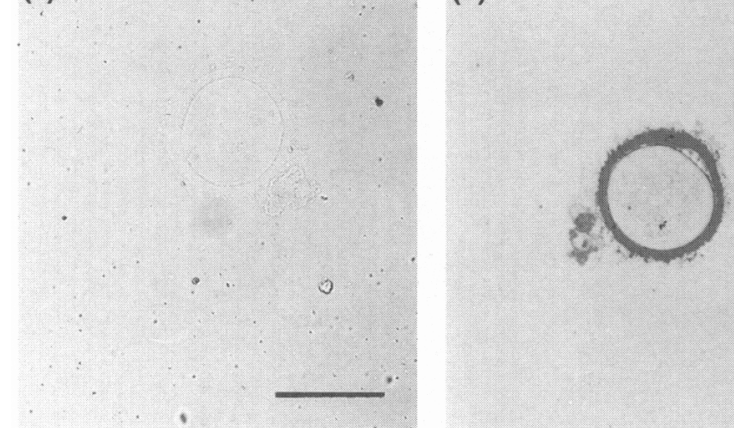

Fig. 2. Araldite section of human oocytes stained with peanut lectin (PNA) (a) before or (b) after treatment of the sections with neuraminidase. Intense binding of PNA to the zona pellucida is seen only in the neuraminidase-treated oocytes. Scale bar represents $100 \mu \mathrm{m}$.

pellucida (Fig. 1a, b, c), whereas that of WGA was considerably more intense at the inner and outer regions of the zona pellucida (Fig. 1d) leaving the central portion of the zona pellucida virtually unlabelled. Unlike WGA, the binding of succinyl-WGA was mainly restricted to the central part of the zona pellucida (Fig. 1e).

The lectins GS-I, SBA, DBA, UEA-I and PNA did not bind at all to the human oocytes (Fig. 2a). However, after treatment of the oocytes with neuraminidase, an intense binding of PNA was found to be evenly distributed throughout the zona pellucida (Fig. 2b).

\section{Ruthenium red labelling}

The binding of ruthenium red to the human oocyte was analysed in thin araldite sections using the transmission electron microscope. Deposition of ruthenium red was mainly observed as clustered material located in the extracellular matrix surrounding the oocytes (Fig. 3). A few dispersed clusters staining with ruthenium red also appeared within the perivitelline spaces. However, within the zona pellucida there was no noticeable binding of ruthenium red, except in occasional granules. There was also no ruthenium red labelling on the plasma membrane of the oocyte.

\section{Discussion}

The present study provides evidence that, as in other mammalian species studied, the zona pellucida of the human oocyte is characterized by a high concentration of saccharide residues capable of binding specific lectins.

By using a large selection of lectins as histochemical markers for zona pellucida carbohydrates, and semithin $(<1 \mu \mathrm{m})$ araldite sections for histochemistry with the light microscope we were able to characterize both the chemical nature and the spatial distribution of the different sugar residues throughout the entire thickness of the zona pellucida.

We have recently shown (Skutelsky et al., 1994) that the zonae pellucidae of different mammals are characterized by unique lectin-binding patterns, which probably represent species-specific variation in their carbohydrate distribution. The lectin-binding pattern of the human zona pellucida has been found in this study to differ from that of other mammals studied (i.e. the human oocyte also displays a species-specific distribution pattern of carbohydrates).

The most pronounced differences between the human zona pellucida and other mammalian zonae pellucidae studied were in the binding of ConA, LCA, S-WGA and PNA. The binding of ConA and LCA, which was relatively high compared with that of other mammals (Skutelsky et al., 1994), indicates the presence of a high concentration of $\mathrm{D}$-mannose residues in the human zona pellucida, probably reflecting a high content of asparagine-linked oligosaccharides. On the basis of a sugar competition assay, Mori et al. (1989) have suggested that the presence of D-mannose residues on the zona pellucida is important in human fertilization.

LCA was previously shown to bind with high affinity to poly- $N$-acetyllactosamine-like glycopeptides, which contain an $\alpha$-L-fucosyl residue attached to the asparagine-linked $N$-acetylglucosamine (GlcNAc) residue (Kornfeld et al., 1981). The presence of high quantities of poly- $\mathrm{N}$-acetyllactosamine was indeed demonstrated in sugar chains of porcine zonae pellucidae glycoproteins (Mori et al., 1991; Yurevicz et al., 1991). The significance of fucosyl residues in human fertilization has also been demonstrated (Huang et al, 1982; Tam et al., 1990), suggesting that L-fucose may be part of a recognition signal between spermatozoa and eggs. At fertilization, the spermatozoon interacts intially with the mature cumulus cells and the extracellular matrix surrounding them, and then binds to the zona pellucida. Tesarik and Kopecny (1986) reported that during the preovulation phase the human oocyte and the cumulus cells both incorporate glucosamine and fucose, which serve as precursors for proteoglycans that can later be found in the zona pellucida and the cumulus intercellular matrix.

The high reactivity of WGA, which was confined mainly to the outer and inner regions of the zona pellucida, may reflect a high content of either GlcNAc or sialic acid residues or both (Monsigny et al., 1980) at these regions. In contrast, the binding of the succinylated derivative of WGA (S-WGA), which is known to bind only to GICNAc and not to sialic acid residues (Monsigny et al., 1980), was generally more intense and was evenly distributed throughout the entire thickness of the zona pellucida. The failure of WGA to bind to the inner portions of the zona pellucida, as opposed to S-WGA, has been previously described in the zona pellucida of rodents (but not in that of canine, feline and porcine oocytes); it was suggested that there are positively charged constituents that interfere with the binding of positively charged lectins, thus preventing them from binding to the inner regions of the zona pellucida (Skutelsky et al., 1992).

The only lectin-binding reactivity that was completely unique to humans was with PNA. This lectin bound intensely to the human zona pellucida only after pretreatment of the oocytes with neuraminidase, a process that cleaves off the terminal sialyl residues, thus exposing normally masked penultimate sugar residues. The ability of neuraminidase to expose PNA-binding sites in the human zona pellucida expresses two unique features of this structure in humans: (1) the presence of cleavable sialyl residues serving as a major terminal sugar in the human zona pellucida; and (2) the existence of high amounts of PNA-binding sugar sequences (i.e. $\beta \mathrm{Gal}-(1-3) \mathrm{GalNAc}$; Lotan 


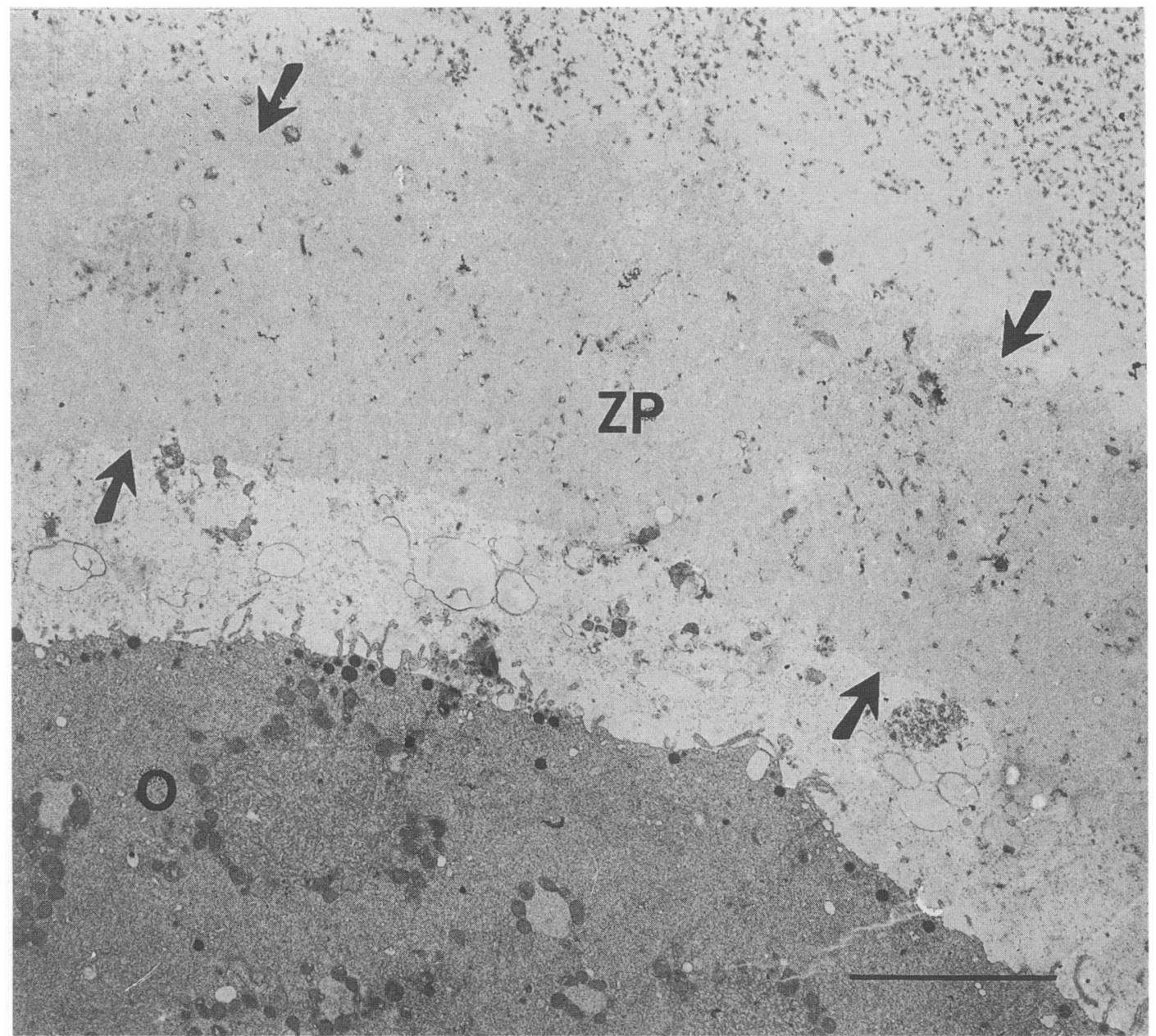

Fig. 3. Electron micrograph of a human oocyte $(\mathrm{O})$ labelled with ruthenium red during fixation. Ruthenium red labelling is seen on cellular fragments in the perivitelline space and in small particles in the extracellular matrix. Except for a few dispersed particles, the matrix of the zona pellucida $(Z P)$ is virtually unlabelled (arrows). Scale bar represents $0.5 \mu \mathrm{m}$.

et al., 1975) only as penultimate to terminal sialyl residues. The existence of PNA-binding sites has been observed in murine oocytes (Skutelsky et al., 1994). However, in mice these sites appeared as normally exposed sugars and neuraminidase treatment did not expose such sites any further. The disaccharide $\beta \mathrm{Gal}-(\mathrm{I}-3) \mathrm{GalNAc}$ was also shown to appear as a major core sequence in $O$-linked neutral sugar chains of porcine zona pellucida glycoproteins (Hirano et al., 1993). However, unlike the human zona pellucida, this sequence in pigs cannot be exposed by neuraminidase, and therefore does not react with PNA (Skutelsky et al., 1994).

Owing to its carboxylic group, sialic acid constitutes a highly negatively charged moiety and, as such, largely contributes to the charge properties of cellular membrane and extracellular matrices. The possibility that the high content of sialylated oligosaccharides in the human zona pellucida might be expressed in a high density of anionic sites was studied using ruthenium red, a polycationic histochemical dye known to interact with carboxyl groups of sialyl residues (Luft, 1971; Skutelsky et al., 1992). In agreement with a previous study (Familiari et al., 1992) our results showed that this dye, which positively stained some extracellular material on both sides of the zona pellucida, failed to reveal such sites in the matrix of the zona pellucida itself. Similar results were previously obtained in the zonae pellucidae of other mammals (Skutelsky et al., 1992), indicating that, despite the high sialic acid content, the human zona pellucida is not negatively charged.

This work was supported by grant No. 91-00096 from the United States-Israel Binational Science Foundation (BSF), and by the Basic Research Foundation of Tel Aviv University. The authors thank L. Ben-Dor and D. Amihay for their technical assistance.

\section{References}

Ahuja KK and Bolwell GP (1983) Probable asymmetry in the organization of components of the hamster zona pellucida Journal of Reproduction and Fertility $6949-55$

Barnum SR and Brown GG (1983) Effect of lectins and sugars on primary sperm attachment in the horseshoe crab, Limulus polyphemus Developmental Biology $95 \quad 352-357$ 
Ben-Nun I, Gethler Y, Jaffe R, Siegal A, Kaneti M and Feijgin M (1990) Effect of preovulatory progesterone administration on the endometrial maturation and implantation rate after in vitro fertilization and embryo transfer Fertility and Sterility 53 276-281

Bleil JD and Wassarman PM (1988) Galactose at the nonreducing terminus of O-linked oligosaccharides of the mouse egg zona pellucida glycoprotein ZP3 is essential for the glycoprotein's sperm receptor activity Proceedings of the National Academy of Sciences, USA 85 6778-6782

Bolwell GP, Callow JA, Callow ME and Evans LV (1979) Fertilization in brown algae. II. Evidence for lectin-sensitive complimentary receptors involved in gamete recognition in Fucus ferratus Journal of Cell Science 36 19-30

Catt JW, Vithanage HIMV, Callow JA, Callow ME and Evans LV (1983) Fertilization in brown algae: further investigations of lectins as surface probes Experimental Cell Research 147 127-135

Chamberlin ME and Dean J (1990) Human homolog of the mouse sperm receptor Proceedings National Academy of Sciences USA 87 6014-6018

Del Pino EJ and Cabada MO (1987) Lectin binding sites in the vitelline envelope of Bufo arenarum oocytes: role in fertilization Gamete Research 17 333-342

Dunbar BS, Wardrip NJ and Hedrick JL (1980) Isolation, physicochemical properties, and macromolecular composition of zona pellucida from porcine oocytes Biochemistry 19 356-365

Familiari G, Mottola SA, Machiarelli G, Micara G, Aragona C and Motta PM (1992) Human zona pellucida during in vitro fertilization: an ultra structural study using saponin, ruthenium red and osmium-thiocarbohydrazide Molecular Reproduction and Development 32 51-61

Florman HM and Wassarman PM (1987) O-linked oligosaccharides of the mouse egg ZP3 account for its sperm receptor activity Cell 41 313-324

Florman HM, Bechtol KB and Wassarman PM (1984) Enzymatic dissection of the functions of the mouse egg's receptor for sperm Developmental Biology 106 243-255

Goldstein IJ, Hughes RC, Mousigny M, Osawa T and Sharon N (1980) What should be called a lectin? Nature 26686

Hirano T, Takasaki S, Hedrick JL, Amano J and Kobata A (1993) O-linked neutral sugar chains of porcine zona pellucida glycoproteins European Joumal of Biochemistry $412763-769$

Huang TTF, Ohzu E and Yanagimachi R (1982) Evidence suggesting that L-fucose is part of a recognition signal for sperm zona pellucida attachment in mammals Gamete Research 5 355-361

Kan FWK, Roux E, St Jaques S and Bleau G (1990) Demonstration by lectin-gold cytochemistry of transfer of glycoconjugates of oviductal origin to the zona pellucida of oocytes after ovulation in hamsters Anatomical Records 226 $37-47$

Kornfeld K, Reitman ML and Kornfeld R (1981) The carbohydrate-binding specificity of pea and lentil lectins. Fucose is an important determinant Joumal of Biological Chemistry $2566633-6640$

Lotan R, Skutelsky E, Danon D and Sharon N (1975) The purification, composition and specificity of the anti-T lectin from peanut (Arachis hypogaea) Journal of Biological Chemistry 250 8518-852.3

Luft HG (1971) Ruthenium red and violet. I. Chemistry, purification, methods of use for electron microscopy and mechanism of action Anatomical Records $171347-368$

Macek MB and Shur BD (1988) Protein-carbohydrate complimentarity in mammalian gamete recognition Gamete Research 20 93-109

Miller DJ and Ax RL (1990) Carbohydrates and fertilization in animals Molecular Reproduction and Development 26 184-198
Miller DJ, Decker G and Shur BD (1993) Egg cortical granule $\mathrm{N}$-acetylglucosaminidase is required for the mouse zona block to polyspermy Joumal of Cell Biology 123 1431-1440

Monsigny M, Roch AC, Sene C, Maget-Dama R and Delmotte F (1980) Sugarlectin interaction: How does wheat germ agglutinin bind sialoglycoconjugates? European Journal of Biochemistry 140 147-153

Mori K, Daitoh T, Irahara M, Kamada M and Aono T (1989) Significance of D-mannose as a sperm receptor site in the zona pellucida in human fertilization American Journal of Obstetrics and Gynecology 161 207-211

Mori E, Takasaki S, Hedrick JL, Wardrip NJ, Mori T and Kobata A (1991) Neutral oligosaccharide structures linked to asparagines of porcine zona pellucida glycoproteins Biochemistry 30 2078-2087

Nicolson GL, Yanagimachi R and Yanagimachi H (1975) Ultrastructural localization of lectin-binding sites on the zona pellucida and plasma membranes of mammalian eggs Journal of Cell Biology 66 263-274

Oikawa T, Yanagimachi R and Nicolson GL (1973) Wheat germ agglutinin blocks mammalian fertilization Nature 241 256-259

Rosati F, DeSantis R and Monroy A (1978) Studies on fertilization in the ascidians: lectin binding to the gametes of Ciona intestinalis Experimental Cell Research 116 419-424

Saling PM (1989) Mammalian sperm interaction with extraceilular matrices of the egg Oxford Reviews of Reproductive Biology 11 339-388

Shabanowitz RB (1990) Mouse antibodies to human zona pellucida: evidence that human ZP3 is strongly immunogenic and contains two distinct isomer chains Biology of Reproduction 43 260-270

Shabanowitz RB and O'Rand MG (1988) Characterization of the human zona pellucida from fertilized and unfertilized eggs Joumal of Reproduction and Fertility 82 151-161

Shalgi R, Maymon R, Bar-Shira Maymon B, Amihai D and Skutelsky E (1991) Distribution of lectin receptor sites in the zona pellucida of follicular and ovulated rat oocytes Molecular Reproduction and Development 29 365-372

Skutelsky E, Bar-Shira Maymon B, Maymon R and Shalgi R (1992) Histochemical characterization of anionic constituents in ooctye-cumulus complex of rats Histochemistry 98 299-304

Skutelsky E, Ranen E and Shalgi R (1994) Variations in the distribution of sugar residues in the zona pellucida as possible species-specific determinants of mammalian oocytes Journal of Reproduction and Fertility 100 35-4I

Tam PPL, Loong EPL and Chiu TTY (1990) Localization of fucosyl glycoconjugates in human oocytes following insemination for in vitro fertilization Journal of In Vitro Fertilization and Embryo Transfer 7 141-145

Tesarik J and Kopecny V (1986) Late preovulation synthesis of proteoglycans by human oocyte and cumulus cells and their secretion into the oocytecumulus complex extracellular matrices Histochemistry 85 523-528

Wassarman PM (1988) Zona pellucida glycoproteins Annual Review of Biochemistry 57 415-442

Wassarman PM (1990) Profile of a mammalian sperm receptor Development 108 1-17

Wu TC, Lee MC, Wan YJ and Damjanov I (1984) Lectin binding sites of the mouse ovary, intraovarian and ovulated ova Histochemistry 80 527-533

Yanagimachi R (1988) Mammalian fertilization. In The Physiology of Reproduction, pp 135-185 Eds E Knobil, JD Neill, LL Ewing, GS Greenwald, C Market and W Pfaff. Raven Press, New York

Yurevicz EC, Pack BA and Sacco AG (1991) Isolation, composition and biological activity of sugar chains of porcine oocyte zona pellucida $55 \mathrm{~K}$ glycoproteins Molecular Reproduction and Development 30 126-134 